\title{
A Study for Detecting Flow Lines on The Aesthetic Plastic Parts During Design Phases as Using Material Flow Analysis Programs
}

\author{
Ayca Kucukoglu*, Sinan Vargelci, Atanur Acar \\ Tofaş Türk Otomobil Fabrikası A.Ş., Bursa, Turkey \\ A. Kucukoglu (0000-0002-1053-6138), S. Vargelci (0000-0003-4353-4865), A. Acar (0000-0002-0945-7811)
}

\begin{abstract}
In today's competitive business environment the automotive industries aim to increase the usage of the plastic materials in automobile components in order to reduce the weight of the vehicles. Although the plastic materials provide a considerable savings on vehicle weight, these materials have some problems to be solved. One of the difficult problems encountered in the production of plastics is the flow lines on surfaces because of its unpredictable behavior. As a result, the considered problem faced by automobile companies often spend plenty of time and money is an issue to resolve. In this study "the source of plastic flow lines on automotive external aesthetical parts" is investigated by using material flow analysis tool of Autodesk Simulation Moldflow $2016^{\circ}$. According to conventional methodologies; weld lines, temperature differences, filling times, clamping forces, shrinkages parameters are examined deeply before tooling phase especially to eliminate aesthetical problems. Considering these conventional methodologies, an unordinary situation was observed, such as flow lines on visible surfaces in the front bumper after the tool stage. Therefore, the flow analysis tool is used simulate these flow lines on the material. Flow directions and flow velocity are comprehensively examined step by step during filling analysis. As a result of the analyzes, the geometric factors that affect the balance of flow and brings turbulence are detected. After the root cause analysis for plastic deformation, different design proposals are analyzed to find the best solution. Analyzes are repeated in the same conditions that are considered to be made for all geometric changes. The experiment results are comparatively analyzed and the solution that has the best flow balance is selected.
\end{abstract}

Keywords: Automotive aesthetical plastic parts, flow lines, mold flow, plastic injection.

\section{INTRODUCTION}

Vehicle manufacturers have been started to compete in order to produce lighter vehicles in a competitive sector that automotive industry [1,2]. Lightweight vehicles bring us advantages such as less fuel consumption and fewer emission values. A general rule of thumb is that for every $10 \%$ reduction in vehicle weight, the fuel consumption of vehicles is reduced by $5-7 \%$ [3]. In this context, producing many parts with plastic material instead of metal material are desired for lightweight vehicles [4]. However, one of the essential problems while producing them for the vehicles is flow lines on the part. Flow lines are the most difficult problems to predict in advance [5]. Therefore, companies spend considerable times and money to solve that problem since it is the most common problem.

There are some main points which can create flow lines on the plastic parts such as injection machine, mold design, material properties, injection parameters and part design $[1,6,7]$. An example for flow line can be seen in Figure 1. Although a flow line on a plastic part can be seen as a simple problem, it is not possible to find out directly these kind of problems with current technologies of material flow simulation software. To observe the source of the problem, the results of the analyses have to be well examined.

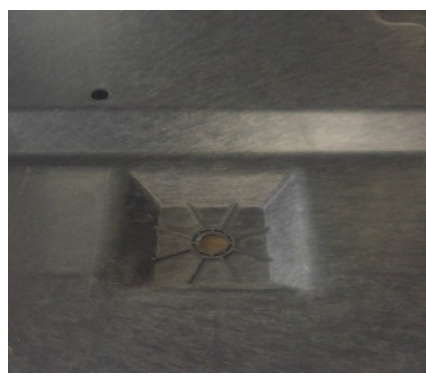

Figure 1: Flow line samples on a plastic part
${ }^{*}$ Corresponding authour

Email: ayca.kucukoglu@tofas.com.tr
European Mechanical Science, June 2019; 3(2): 68-74 doi: https://doi.org/10.26701/ems.481761

Received: November 11, 2018

Accepted: April 21, 2019 
Flow lines are the lines that are visible on the surface of the plastic part. It has same color with part but has different tone in color. It occurs during the production phase of plastic injection. Flow lines can be caused by mostly injection parameters such as uneven cooling, uneven injection pressure, inadequate fill time, less melt temperature improper venting, wrong runner selection. Furthermore, it depends on the geometrical shape of the parts as well. Flow lines are not desired especially aesthetical parts such as in automotive sector. In this study flow line issue on front bumper has been studied. Flow directions and flow velocity are studied detailed. Different design solutions has been compared in order to see flow line generation.

The rest of the paper is organized as follows. Section 2 describes the considered solution methodology. In section 3 results of the experiments are discussed. In section 4 conclusion part is given.

\section{MATERIALS AND METHODS}

\subsection{Injection Molding Process}

Plastic injection is a manufacturing method that includes injection of the hot raw material to the inside of the mold and removing of the part as cooling from the mold. Many plastic parts such as smaller parts, garden furniture, automotive plastics, etc. can be manufactured by that method. This method is performed by plastic injection machines as seen in Figure 2 [7]. Simply, manufacturing process of a plastic part by injection includes clamping, injection, packing, cooling, mold opening and ejection steps which are given below [9, 10]. The details of these operations are given below.

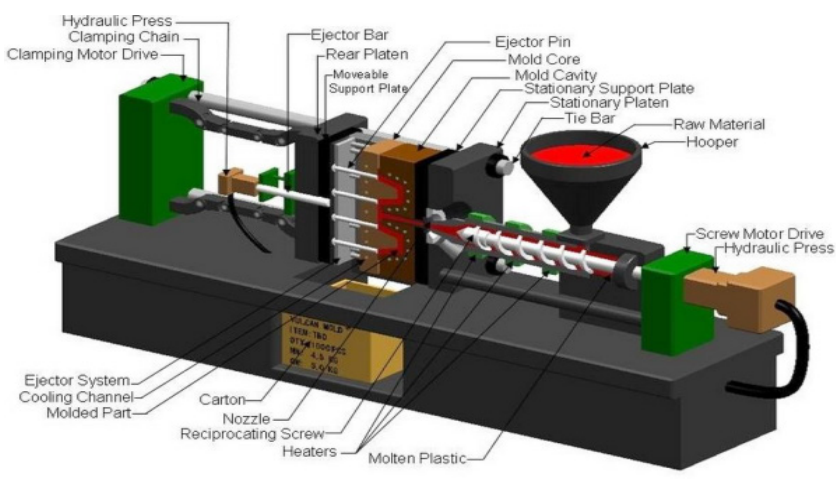

Fig. 2 Plastic injection machine [11]

\section{Clamping}

An injection machine consists of three parts as clamping unit, injection unit, and mold. Clamping unit holds the mold under a pressure during the injection and cooling steps of the process. Simply it unites the two parts of the injection machine (cavity and core units) $[8,10]$

\section{Injection}

The plastic raw material is transported to a chamber on the injection machine during the injection process [8]. After that these raw material is transported into a cylinder which is heated by resistances by a screw which is controlled by electronically. That screw shifts the plastic melt which is made by pressure and high temperature application of the screw. The injection process is started after the filling enough of the plastic into the cylinder. Plastic melt is transferred by an injection nozzle on the outside of the mold [8]. Pressure and velocity are controlled by a hydraulic motor during the process [9].

\section{Packing}

Packing process has been performed in order to prevent such as warpages, shrinkages, etc. In that step, it is provided to fill the plastic melt to mold completely by applying a pressure. That step continues until the plastic melt becomes solid. The period of that step varies respect with raw material properties, dimensions and weight of the part [12].

\section{Cooling}

Solidification of the plastic melt has been provided by the cooling step of the process. Plastic part which is solidified in the mold can be used in almost every industrial area. Cooling of the mold is provided by cooling canals of the mold [8].

\section{Mold Opening}

Once the previous processes completed sufficiently, mold becomes ready to mold opening phase. Mold is opened automatically in that process by hydraulic systems. Thereby injected part becomes ready to ejection.

\section{Ejection}

Finalized plastic parts are ejected by cores and ejectors according to the mold type. Plastic melt tends to solidify before filling entirely if proper pressure value has not been selected in order to produce plastic parts. That means insufficient packing on the plastic part. Insufficient packing causes the flow lines on the plastic parts. For this reason, proper pressure value selection has importance in the injection process $[7,13]$.

\section{Mold Design}

Mold is one of the parts of the injection machine that plastic melt is filled up. Mold is a particular study subject because of the product design variety [10]. Used parts have high costs due to material types and high tooling costs. Consideration of the parameters and designing of the mold is possible in one step by modern technology. A simple mold is shown in Figure 3.

If mold is designed with an insufficient cooling system, plastic melt solidifies early and solid plastic cannot be packed and so visual problems occur $[4,8,12]$. 


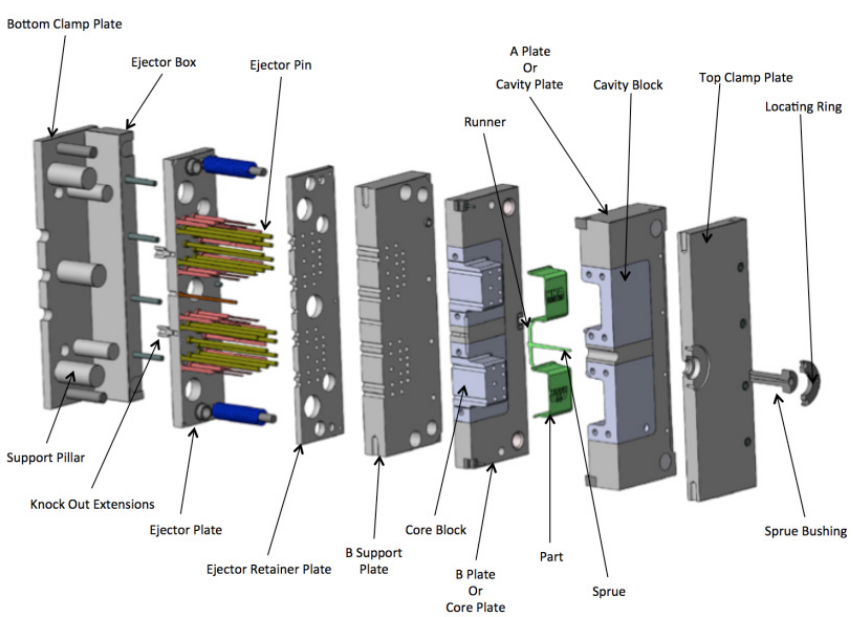

Fig. 2 Plastic injection mold [14]

\subsection{Material Selection}

Every plastic manufacturer produces raw materials according to its formulation. Every material has particular liquidity. That liquidity varies according to the material manufacturer [15]. Increasing plastic melt liquidity causes difficulties such as filling the mold entirely and moving the plastic melt. Plastics which has less liquidity do not provide needed technical properties. For this reason, it is important that selection of the material which provides us needed technical properties and which does not cause turbulence in the mold [16].

\subsection{Part Design and Material Flow Analysis}

Part design is the 3D designing of the part which can operate the expected functions, and that can prevent the visual problems. Moldability, sufficient durability, and staying away from the geometries that can cause aesthetic problems should be considered as designing a plastic part [8]. The convenience of the molded plastic part can be validated by analyzing on a computer with current technologies. Using that kind of technologies allow us to determine optimum shape of the design and improvement needs and to check the thickness of the part, the alignment of the geometric tolerances, moldability, and cost of the part. Filling of the mold and examination of the visual problems of the designed parts can be carried out by Autodesk Moldflow analysis which is known as the most common software for this kind of applications. Filling analysis, short shut effects, warpage effects, shrinkage effects, determination of the weld line, injection locations and injection machine press tonnage are the main parameters that are checked during the design step [13]. These parameters are described at follows.

\section{Fill Analysis}

The fill analysis predicts the thermoplastic polymer flow inside the mold in the filling phase. This is the first step of any injection molding simulation. It is considerably important to perform that first due to that analysis is able to give some predictions to analyzer such as gate location, weld line position, flow balance and hesitation.

\section{Short Shut Effects}

A short shut is the incomplete filling of a mold cavity which results in the production of an incomplete part. Figure 4 shows a sample of short shut effect. Molten plastic does not fill the cavity completely. The flow freezes off before the flow paths have completely filled. The part is needed to be adequately packed. Also material type and its viscosity at moulding temperature is important. Therefore mould and molten temperature have to be propor in order to avoid short shuts. [17].
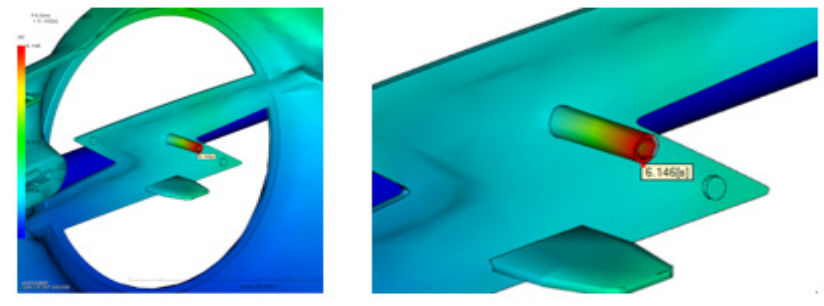

Fig.2 Short shut effect

\section{Warpage Effects}

Warpage means dimensional distortion caused by a non-uniform change of internal stresses. Figure 5 shows a warpage sample. To avoid warpage because of the design, the part thickness should be equal. Variable thickness causes non-uniform cool and warpage.
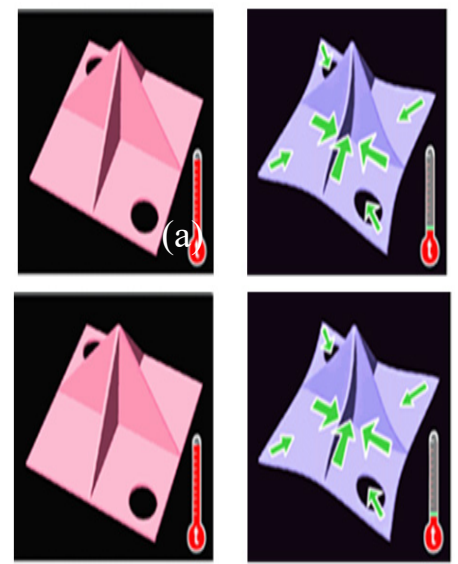

Fig.2 Warpage effects [18]: (a) Part before cooling (b) Part after cooling

\section{Shrinkage Balance Effect}

The reduction in the dimensions of a plastic part compared with the mold dimensions. Shrinkage occurs as the polymer cools and can vary in different directions. To avoid non-uniform shrinkage because of the part design, the part thickness should be equal. Variable thickness causes non-uniform shrinkage [17]. 


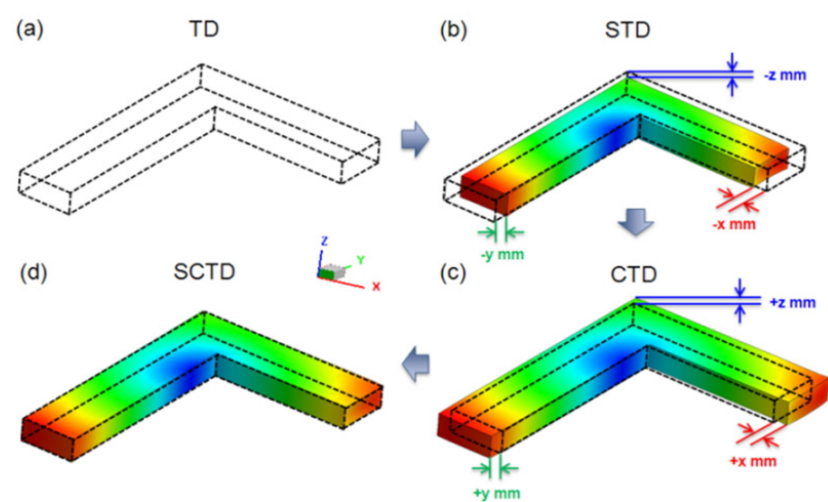

Fig. 6 Shrinkage effect [19]: (a) Target Design (TD) (b) Simulation result of the Target Design (STD) (c) Compensate Target Design is the modified design with the reverse of STD shrinkage (CTD) (d) Simulation result of the Compensate Target Design (SCTD)

\section{Weld Line Location}

A weakness or visible flaw created when two or more flow paths meet during the filling process. Weld lines can be caused by holes or inserts in the part, multiple injection gates, or variable wall thickness where hesitation or "race tracking" can occur. Weld line location can be seen in Figure 7. If the different flow fronts have cooled before the meeting, they may not recombine well, causing a weakness in the molded part. A line, notch, and/or color change can also appear. To avoid weld lines because of the part design, the part thickness should be equal. Variable thickness causes weld lines [17].
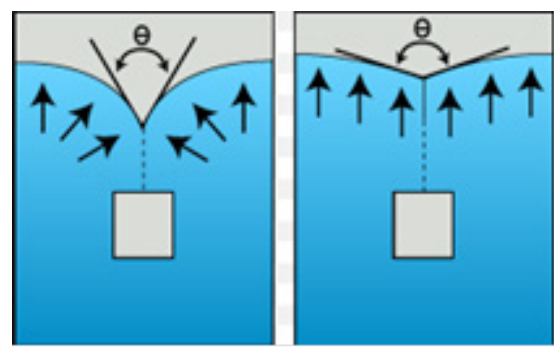

Fig. 7 Weld line location [20]

\section{Definition of Injection Locations and Quantity}

The injection location represents the position where the polymer is injected, enabling the software to simulate the flow pattern inside the mold cavity. According to design, gate location and quantity can change, for the optimum amount of gate quantity and optimum location, the part design should be uniform. Otherwise, unbalanced flow occurs and it causes some problems on parts. Figure 8 shows the differences between unbalanced and balanced flow. (a)

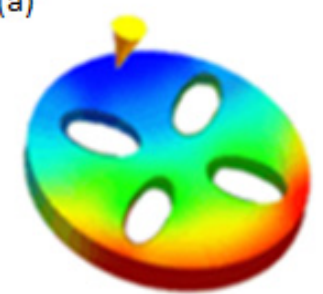

(b)

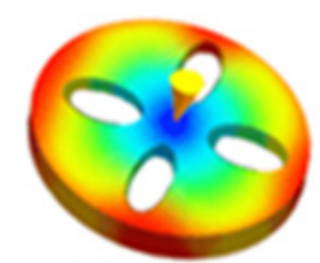

Figure 8: Balance and unbalance flow effects [21]: (a) Unbalanced flow effect (b) Balanced flow effect

\section{Definition of Injection Machine Press Tonnage}

The clamping force is the maximum force required to keep the mold closed during filling. This force can be calculated. The clamp force predictions for a part can then be compared with the clamp force limit of the injection molding machine to be used. To avoid high clap force, the part should not have high injection/packing pressure. To reduce the injection/packing pressure, the wall thickness of the part can be increased.

\subsection{Introduction of the Front Bumper}

A bumper is the biggest plastic aesthetical and structural part of a vehicle. It includes fog lamps, grills, chrome parts, logo and sensors on it. Due to the aesthetical role of the bumper, its relationship between adjacent parts and also its relationship between the parts that on it are important for the external view of the vehicle. Also due to its plastic structure, material, manufacturing quality and painting quality, etc. are the main parameters that should be considered. These parameters are entirely important for the perceived quality of the customers.

Another important thing about the bumper is the passenger security. Due to the energy absorber ability of the plastics, there are some occupant protection regulations. For this reason, during the design phase, these regulations must be considered in addition to the other parameters such as manufacturing method, quality, durability, etc.

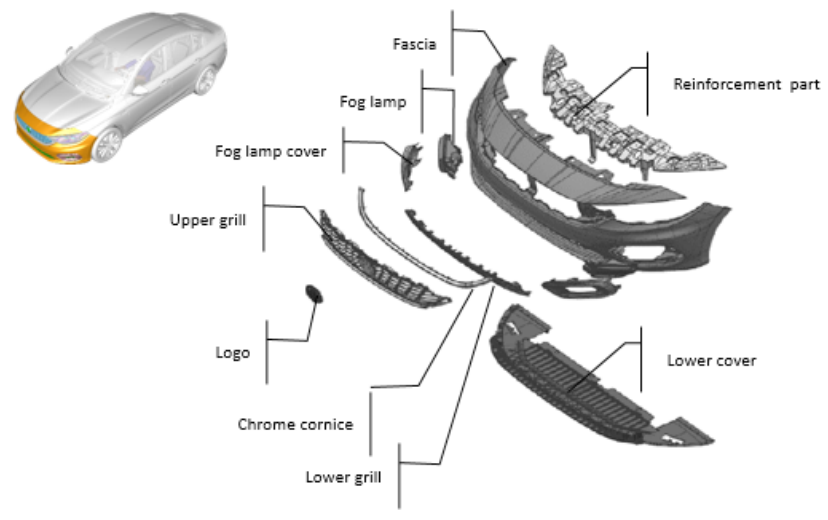

Fig. 9: Front Bumper

\subsection{Root-Cause of the Flow Line Issue and Validation of Design Solutions}

The detection of the flow lines on existing front bumper has been analyzed on Autodesk Simulation Moldflow 2016 software. Current production bumper and different design solutions have been analyzed in order to see root cause of flow lines and how material flows in problem zone. As seen in Figure 10, there exists a flow lines on the aesthetical area of the front bumper.

In order to find root cause of the problem current design has been controlled considering of filling time, warpage effects, shrinkage effects, weld lines and temperature analysis. However, analysis software does not show any sign about the flow lines. 

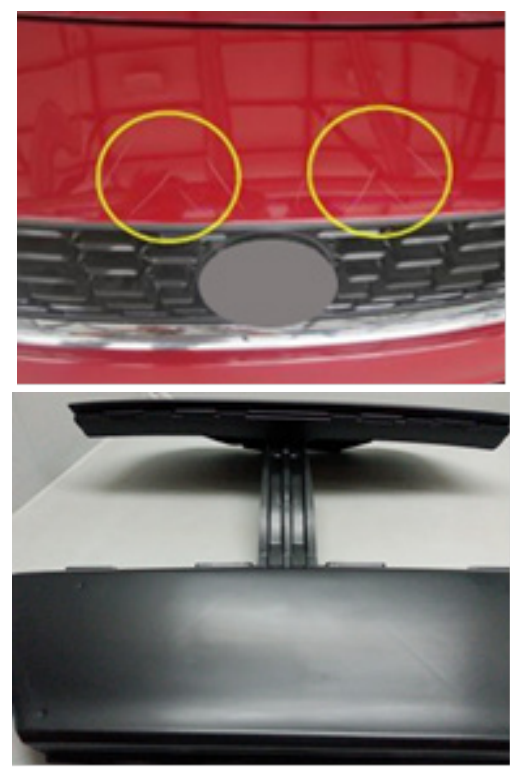

Fig. 10 Front bumper flow line problem

There are not any issue which can create surface errors according to results. As seen in Figure 11 and Figure 12, filling is balanced and surface temperature differences are adequate. Also warpage and shrinkage effects are acceptable.

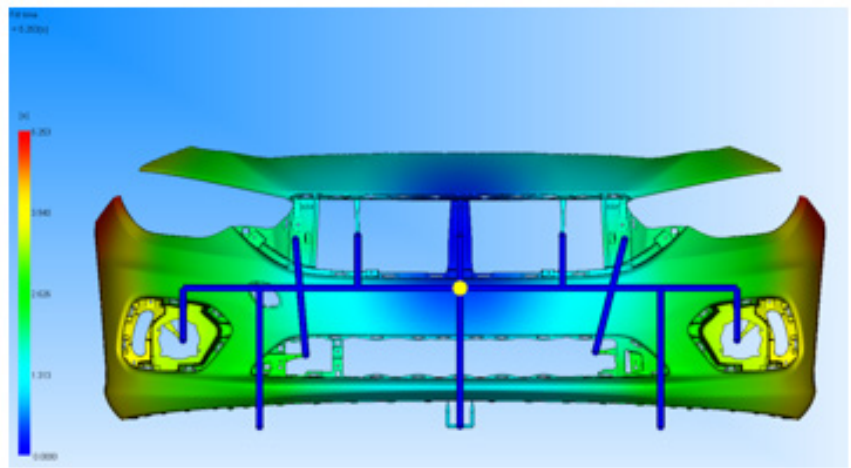

Fig. 11 Front bumper homogenous filling analysis result

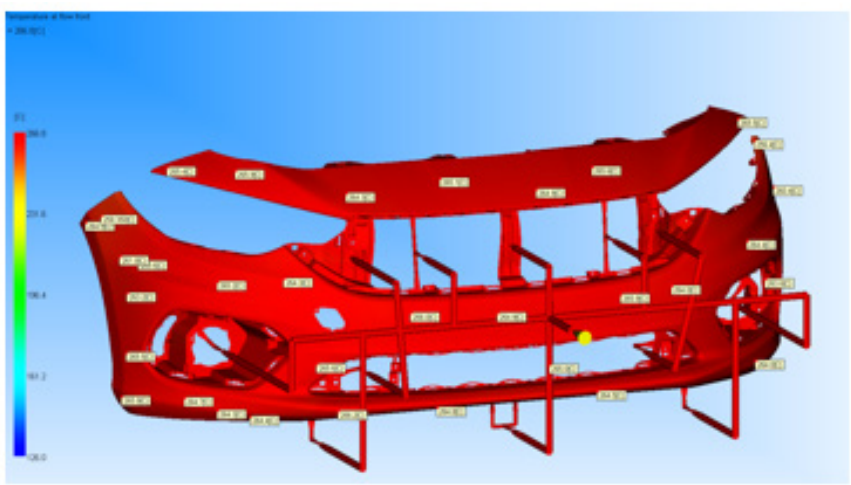

Fig. 12: Front bumper surface temperatures analysis result

Production has been started with these positive results, but surface flow line problems have occurred after the production. Even after painting these flow lines were still visible. After checking the current Moldflow results issue zone was checked in terms of its geometrical shape.

In the current bumper, there are some geometric shapes as shown in Figure 13 such as rib features that can affect the direction of material flow, create turbulence and causes flow lines on the visible surface

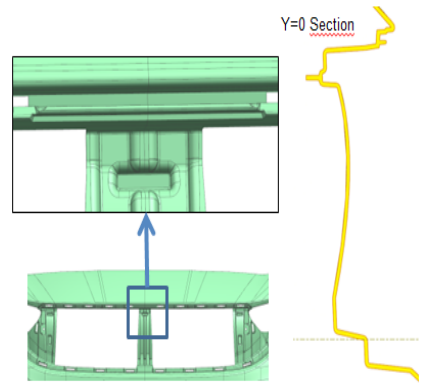

Fig. 13 Focused zone around flow line issue

Results of the mold flow analysis of indicated zone are seen in Figure 14. It is seen that during the first $0.27 \mathrm{~s}$ of the flow process, plastic melt flows balanced and filling is performed simultaneously in everywhere. After the 0.1 second later, so at the 0.37 second of the process, unbalanced flow and different flow rates near the walls are seen in Figure 14. These different flow rates are seen in the results flow speed of the analysis. In Figure 15, some speed differences are seen which can cause turbulence and also flow speeds were changed after raw material passed that zone and arrive aesthetical zone.
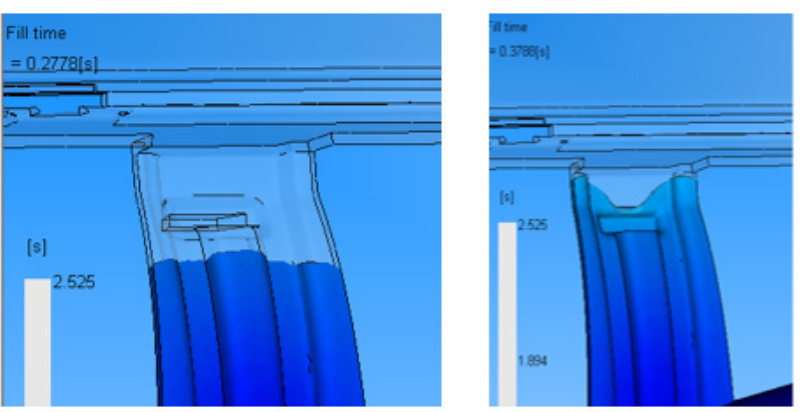

Fig. 14 Result of the flow analysis at $0.27 \mathrm{~s}$ and $0.37 \mathrm{~s}$.

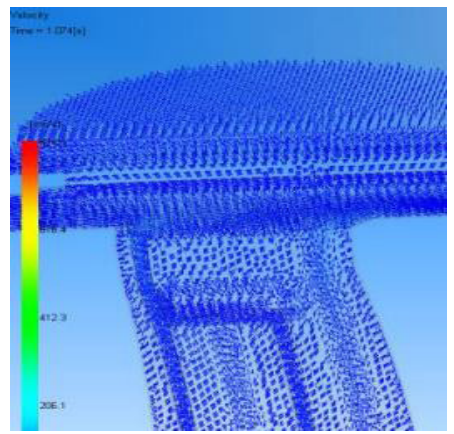

Fig. 15 Flow speed results of the analysis at the $0.37 \mathrm{~s}$

In order to prevent turbulence and flow speed changes on aesthetical surface different design studies analyzed. There are three different proposals to change current geometry for the solution of the problem. As seen in Figure 16, two canals have been added in order to control the flow. Hardly, that design proposal has not worked and differences on the flow speeds continue. 

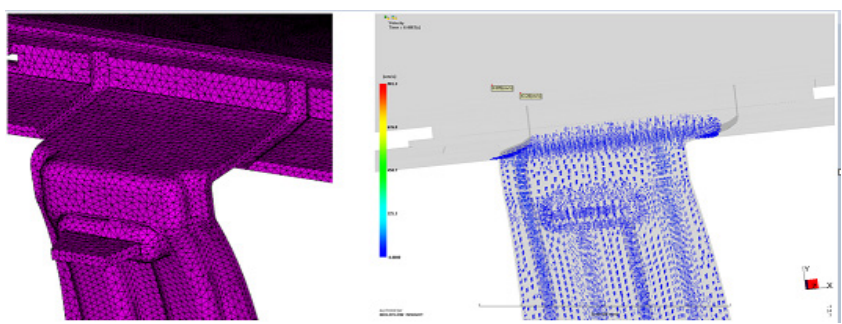

Figure 16: Design proposal 1 - control canals and analysis results

As seen in Figure 17, rib structure has been changed, but that proposal was not enough to prevent the problems which was flow speed differences.
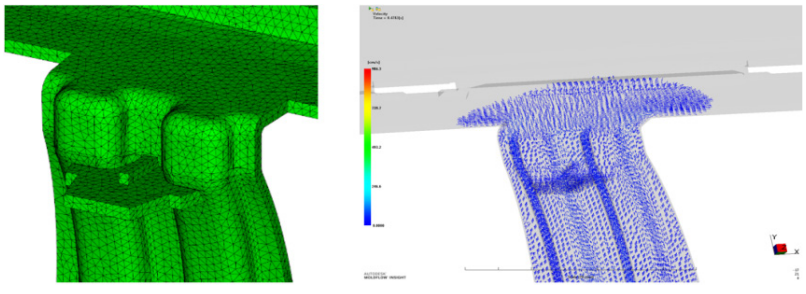

Figure 17: Design proposal 2 - control canals and analysis results

Root-cause that comes from results of the existing situation analysis is that existence of the shapes that prevent the flow and cause the turbulence. Presence of a small pool behind the rib which is used for assembly of the bumper causes flow lines on the visible surface. Additionally, a ribbed structure which links the upper and lower portion of the bumper causes the unbalanced flow.

Figure 18 shows a proposed design model which has not shapes that cause turbulence anymore. More balanced flow and sufficient flow speeds and non-cross flows are predicted with that model.
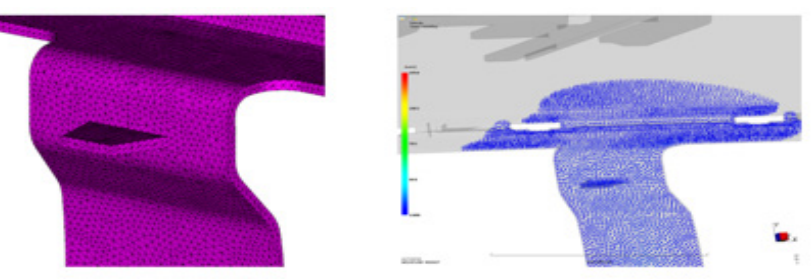

Figure 18: Design proposal 3 - More smooth transition for material flow
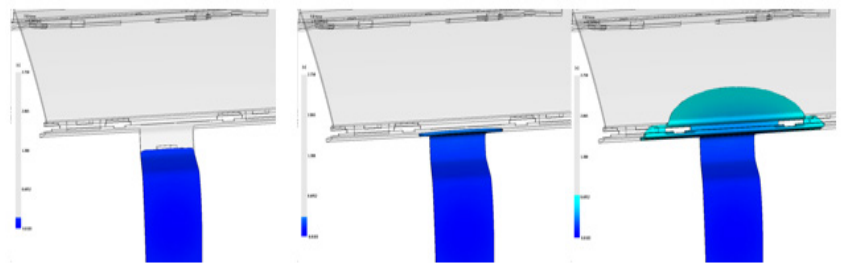

Figure 19: Analysis results of Proposal 3 at $0.20 \mathrm{~s}, 0.34 \mathrm{~s}, 0.72 \mathrm{~s}$ of the flow analysis

Balanced flow and solidification of the proposed design model are seen in Figure 19. According to the results of the flow analysis, the flow has been balanced and turbulence problem was eliminated.

\section{RESULT AND DISCUSSIONS}

It is observed that current and design proposal $1 \& 2$ have flow problems due to their geometrical shapes. Those geo- metrical shapes are located before the aesthetical surface. During the material flow that shapes cause flow speed differences and turbulence on flow and this creates flow lines on the plastic surface. By the final design proposal 3, that geometrical shapes eliminated and turbulence problem of the flow has been eliminated. So that flow continues balanced and flow line issue has been solved by new design.

\section{CONCLUSIONS}

Determination of the flow lines of plastic materials in advance is a difficult problem. Also, it is difficult to determine that kind of problems on the material flow analysis software. Since currently material flow analysis are not able to show as a direct result of the analysis such as warpage and shrinkage effects which are seen directly in numerical value in results. In this study, it has been seen that interpretation of result become more important in terms of flow lines issues. For this reason, flow results of the mold flow should be examined carefully. It must be considered with temperature and pressure values as well. It must be deeply examined where raw material passes and arrives to visible aesthetical surface during flow in terms of flow speeds and turbulence effects. Design features should not affect directly the material flow.

In this study a flow line issue on aesthetical surface of front bumper has been studied. Flow line problem has been solved by using the final proposal and modifying the mold. Flow line interpretation and determination during the design and analysis phase of the project significantly became more important after this study. It is necessary to be considered detailed during the project in order to prevent quality, money and time losses.

\section{REFERENCES}

[1] Akbarzadeh A., Sadeghi M. (2011). Parameter Study in Plastic Injection Molding Process using Statistical Methods and IWO Algorithm. International Journal of Modeling and Optimization pp. 141.

[2] Lopes, N., \& Ribeiro, B. (1999). Part quality prediction in an injection moulding process using neural networks. proceedings of WMC, ISM.

[3] Cheah, L. W. (2010). Cars on a diet: the material and energy impacts of passenger vehicle weight reduction in the US (Doctoral dissertation, Massachusetts Institute of Technology).

[4] Taghizadeh, S., Özdemir, A., \& Uluer, O. (2013). Warpage prediction in plastic injection molded part using artificial neural network. Iranian Journal of Science and Technology. Transactions of Mechanical Engineering, 37(M2), 149.

[5] Guo, W., Hua, L., Mao, H., \& Meng, Z. (2012). Prediction of warpage in plastic injection molding based on design of experiments. Journal of Mechanical Science and Technology, 26(4), 1133-1139.

[6] Park, K., Sohn, D. H., \& Cho, K. H. (2010). Eliminating weldlines of an injection-molded part with the aid of high-frequency induction heating. Journal of mechanical science and technology, 24(1), 149-152.

[7] Rosato, D. V., \& Rosato, M. G. (2012). Injection molding handbook. Springer Science \& Business Media.

[8] Harper, C. A. (2006). Handbook of plastic processes. John Wiley \& Sons. 
[9] Frizelle W.G. (2016). Applied Plastic Engineering Handbook. 2nd ed. Part II. Chapter 10. pp. 191-203.

[10] Fuh, J. Y., Fu, M. W., \& Nee, A. Y. C. (2004). Computer-aided injection mold design and manufacture. CRC Press.

[11] http://www.rpm-engineering.com/plastic.html

[12] Rännar L.-E. (2008). An Optimization of Injection Molding Cooling. pp. 5-11.

[13] Wang, J. (2012). PVT properties of polymers for injection molding. In Some Critical Issues for Injection Molding. IntechOpen.

[14] http://ayannaplastics.com

[15] Dealy, J. M., \& Wissbrun, K. F. (2012). Melt rheology and its role in plastics processing: theory and applications. Springer Science \& Business Media.

[16] Larson, E. R. (2015). Thermoplastic Material Selection: A Practical Guide. William Andrew.

[17] Autodesk Moldflow Troubleshooting Guide. 'https://knowledge.autodesk.com/support/moldflow-insight/learn-explore/caas/ CloudHelp/cloudhelp/2017/ENU/Moldflowlnsight/files/GUID-3E3EFE66-AE31-4E50-831E-5944C5820ED6-htm.html'.

[18] https://knowledge.autodesk.com/support/moldflow-flex/learn-explore/caas/CloudHelp/cloudhelp/2014/ENU/Moldflowlnsight360/files/GUID-8A317780-B538-40FB-9AD4-CB04B13FA82Ehtm.html

[19] http://www.moldex3d.com/en/newsletter/achieve-plastic-part-dimension-accuracy-through-3d-volume-shrinkage-compensation-method

[20] https://knowledge.autodesk.com/support/moldflow-flex/learn-explore/caas/CloudHelp/cloudhelp/2015/ENU/Moldflowlnsight360/files/GUID-099634AE-DB7A-41BA-B70C-5A23FB013B06htm.html

[21] https://knowledge.autodesk.com/support/moldflow-insight/learn-explore/caas/CloudHelp/cloudhelp/2017/ENU/Moldflowlnsight/files/GUID-706D3A91-F6EE-4577-8186-9381D967E13A-htm. html 